\section{THREE CASES OF SARCOMA OF THE UTERUS.}

BY E. OCTAVIUS CROFT, M.D. DURH.,

HONORARY SURGEON TO THE HOSPITAL FOR WOMEN AND CHILDREN, LEEDS ; DEMONSTRATOR OF OBSTETRICS IN THE YORKSHIRE COLLEGE, LEEDS.

PRIMARY sarcoma of the uterus is undoubtedly a very uncommon disease, but in all probability its rarity is considerably over-estimated. Such a large number of cases of malignant disease of the uterus come under observation only when the disease is so far advanced that anything more than palliative treatment is impossible and therefore a carefal pathological examination of the nature of the growth is not made and it is possible that many of these cases may have been of sarcomatous rather than of carcinomatous malignancy.

Mr. Roger Williams in his recent book ${ }^{1}$ states that his analysis of 2649 consecutive cases of primary uterine neoplasms comprises only two examples of sarcoma to $157 \mathrm{~L}$. cancers. He does not state whether these were all confirmed pathologically, but I presume that they were. Recently, however, interest has been aronsed in this disease and cases are being recorded more frequently. The following cases are therefore, I think, worthy of reporting, especially as they exemplify three very distinct varieties of the disease both in their clinical and pathological features.

OASE 1.- The patient was a married woman, aged 39 years, who had had one child and who had had no abortions. Menstruation, which commenced at the age of 14 years, was regular, copious, and not very painful. The patient was married in 1893. About six months after her marriage the menstrual flow increased and she was operated upon for something which was said to have protruded from the vulva when she strained. In 1895, the menorrhagia having returned, she came under my care at the Hospital for Women and Children at Leeds and I found and removed several polypi from the cervix and the uterine cavity which was scraped. These growths had all the appearances of ordinary mucous polypi. The condition of the patient so far improved that a few months afterwards pregnancy occurred and her only child was born after a normal labour at the end of 1896 . About six months after confinement and on two subsequent occasions some polypoid growths were treated by various surgeons, on the last occasion the operation being stated to have been radical. On May 13th, 1899, the patient returned to the hospital for urgent bleeding and severe anæmia. The uterus was found to be enlarged and a polypoid mass of growth of about the size of a fist occupied its cavity. This was scooped away and the cavity was cleansed and packed with ganze. It was then found that there was a further growth in the left wall of the uterus. Examination of the tissue which had been removed proved it to be undoubted sarcoma. When her general condition had improved ether was given with a view to radical operation if found possible. It was then found that in addition to the growth in the uterine wall a further large mass existed burrowing deeply between the layers of, and at the base of, the left broad ligament. It also extended upwards above the brim of the pelvis and was closely related to the bladder in front and the rectum behind. The disease was clearly irremoveable. The growth then slowly increased and occasional attacks of bleeding required treatment by packing. The patient's health steadily failed. Twelve months afterwards she was again in the hospital, the discharge, which had become foul, having produced septic symptoms. The growth was then found to bave increased greatly. A large mass occupied the lower half of the abdomen, three rounded masses being especially prominent. One of these conld be identified as the uterus enlarged with an intranterine mass. The sepsis was relieved, but the patient gradually became weaker and she died from exhanstion in September, 1900. A noticeable and fortunate circumstance in the case was an almost entire absence of pain throughout. There were no symptoms or signs indicating the presence of secondary growths in other organs.

The nature of the growth, which was examined on several occasions, proved to be an undoubted round-celled sarcomatous infiltration of the uterine tissue. There was no evidence of any structures in the specimens which might suggest the case to have been one of deciduoma malignum. The fact, however, that the polypi which were removed before the pregnancy were apparently innocent and that the malignancy of the disease asserted itself a few months after confinement is a point of great interest. If the exact nature of the growth had been ascertained on its recurrence after the confinement it is possible that a radical operation (bysterectomy) at that time might have saved the patient. The condition was only discovered when secondary growths rendered operation impossible.

CASE 2.-The patient, a widow, aged 66 years, was the mother of four children. Her last confinement had taken place at the age of 40 years. The menopause occurred naturally in her forty-sixth year. For seven or eight years there had been a slight, occasionally blood-stained, discharge from the vagina, but this discharge had become much increased during the last few months. She complained of very little pain until about six weeks before I saw her, but during that time the pain in the lower abdomen had been severe. There had been marked loss of flesh recently. On examination there were great pain and tenderness in the hypogastric region, so much so that thorough examination was impossible. Vaginal examination revealed a patulous cervix free from disease, an enlargement of the uterus, and an offensive blood-stained discharge issuing from its cavity. The patient. was examined under ether. The nterus was then found to be generally enlarged, its fundus reaching two or three inches above the pubes, and there was evidently some peritoneal effusion and adhesion. The interior of the cavity of the uterus was found to be roughened and irregular with. new growth which was specially abundant near the fundus. This part was necrotic and it easily broke down. Owing to the presence of the peritonitis and the general condition of the patient extirpation was impossible. The uterine cavity was cleansed as far as possible of foul tissue and was packed with iodoform ganze. Portions of the growth were preserved for examination. The patient did not improve and eventually she died from the peritonitis.

The growth consisted of a very vascular sarcoma consisting of bundles of spindle cells with many vessels and much blood. It is probably an example of the diffused sarcoma of the connective tissue of the uterine mucous membrane.

CASE $3 .^{2}-A$ married woman, aged 32 years, the mother of four children. was sent to me in June, 1898, by Dr. C. J. R. McLean of Yeadon for metrorrhagia following the expulsion of a vesicular mole. Menstruation, which commenced at the age of 14 years, was never regular, the flow appearing about every six or eight weeks and lasting for two or three days. It was then scanty and painless. The patient had married when she was 26. years of age, and having had four pregnancies in rapid succession and three of the infants having been suckled menstruation was practically absent during the whole of this period. The labours were all difficult. The second child was delivered stillborn with instruments. The fourth and last child was born two years before I saw her and she had never been well since, but always anæmic and weak. The child was suckled for 18 months, and soon afterwards menstruation returned two or three times and then followed a flooding. The uterus then rapidly enlarged, and the flooding recurring a vesicular mole was diagnosed and the uterus was cleared by Dr. McLean. The uterus shrank and the bleeding ceased, but a watery discharge continued, increased, and became offensive and occasionally bloody. When sent to me the patient was extremely anæmic and her temperature was $103^{\circ} \mathrm{W}$. The os was patulous, the cervix was soft, and the uterus was enlarged, the sound passing three and a half inches, and freely moveable. Under ether the uterine cavity was explored. The finger detected a rugged friable mass attached to the upper and posterior part of the uterine wall. It gave the impression of a malignant growth. The free portions were carefully removed with a scoop and the cavity was irrigated and packed with iodoform gauze. The growth was preserved for examination. The septic condition subsided and the patient improved. The growth was examined independently by several pathologists who all agreed that it was sarcoma.

2 The specimen from this case was shown at a meeting of the Leeds and West Riding Medico-Chirurgical Society in October, 1898. 
The report of the Clinical Research Association was to the effect that the tissue consisted of uterine muscle substance infiltrated with sarcoma. The cells were spindle-shaped and many of them were very large. The characters of the growth were not like those of deciduoma malignum. The iterus was consequently extirpated by vaginal hysterectomy and the patient made a good recovery. I examined the patient a few months ago-that is, just two years after the operation-and I found her to be free from disease and in good general health. I have recently heard that she continues well.

The uterus when removed showed no signs of growth externally. On opening its cavity by a vertical incisiun through the anterior wall the disease was seen to consist of a small, reddish, lobulated sessile growth situated on the upper and posterior part of the uterine wall and projecting towards its cavity. The other portions of the uterine wall presented no naked-eye evidence of disease. Further microscopical examination of sections direct from the growth after removal confirmed the previous diagnosis.

Leeds.

\section{A CASE OF RECOVERY AFTER OPERATION FOR DIFFUSE PERITONITIS FROM PERFORATION OF THE APPENDIX}

By RUSSELT COOMBE, M.A., M.D. Cantab., F.R.C.S. ENG.,

SURGEON TO THE EXETKR DISPENSARY.

THE case which I have described below may prove of interest when read in conjunction with the case reported by Mr. Charles A. Morton. ${ }^{1}$ The infection was obviously widespread, as in that case, but I acted in the operation on the belief that the upper part of the general cavity was free and that it was my business to leave it so. On the other hand, the pelvic part of the cavity was full of dirty fluid, which was most thoroughly sponged out and the cavity drained. The consecutive abscess in the left scrotum was doubtless due to a patent funicular process on that side.

On March 1st, 1901, I was asked by Dr. A. Macindoe of Sidmouth to see a patient a boy, aged 14 years. The past history of the patient was unimportant, there being a record of an occasional stomach-ache but nothing more. The boy was perfectly well on Feb. 25th. On the next morning he had some pain which he referred to the region of the appendix. He felt sick and had lost his appetite, but he sat up all day. He was first seen by Dr. Macindoe's locumtenent on the morning of the 27th. He had had some shivering during the night and had begun to be sick, with severe abdominal pain which had kept him awake all the night. The vomit was at first bilious, becoming darker afterwards. The bowels had acted. The abdomen was distended, more especially on the right side. The temperature was $104^{\circ} \mathrm{F}$. Dr. Macindoe first saw. him on the 28th. He was still very sick and the abdomen was much distended.

I visited him late in the afternoon of March lst when the sickness had stopped, but the boy was obviously very ill. His temperature was $102^{\circ}$, his pulse was 132 , and his respirations were 36 . He had a hard, dry, red tongue with moist edges, and the respiration was chiefly thoracic. The lad lay on his side with his legs drawn up. The abdomen was generally swollen. but it was very markedly so in the neighbourhood of McBurney's point, there being already some redness and cedema in that situation. It was impossible to operate that night, but as early as possible on the next day (March 2nd) I opened the abdomen by an oblique incision reaching as far down as the deep epigastric vessels. On dividing the peritoneum at the upper part of the wound I at once came on an abscess extending upwards ontside the ascending colon towards the liver. The pas, which had a strong fæcal odour, was carefully sponged out of this. The edge of the omentum, which lay on the inner side of the wound between the large bowel and the parietes, was not disturbed at the npper part, as there was a little glueing together of the peritoveal surfaces, but in the direction of the pelvis there was not

1 The Lancht, April 20th, 1901, p. 1134. the faintest attempt at any barrier and the fingers passer right down into the pelvis to the roof of the bladder, a large quantity of dirty brown-tinted blood welling up as the coils of intestine were separated. This fluid was sponged away as it welled up, and when this ceased the sponges were continually passed down into the pelvis until they returned dry. Two large drainage-tubes were then inserted, one going to the sub-hepatic pouch, the other down into the pelvis. The appendix itself was not seen.

The after-treatment was simple. Half a grain of calomel every hour for eight hours and a rectal tube did wonders in relieving the abdominal distension. A concretion of the size of a buttier bean came away from the upper part of the wound on March 27th, the wound healing entirely a few days later. The only drawback during convalescence was that on the third day after the operation the scrotum became ir flamed and an abscess slowly developed in the left tunica vayinalis. This was opened on March 13th and about three ounces of very foul pus escaped. The boy is, I hear, now about and well.

Exeter.

\section{ON THE USES OF DLPHTHERLA ANTITOXIN.}

BY T. B. BROADWAY, M.B., B.OH. GLASG.

AT a time when the antitoxin treatment of diphtheria is still in its ixfancy, when there are many who use it doubting its value-hence tardily and inefficaciously-and still a few who bave no faith in its efficacy whatever, the putting in black and white of the successtul cases that have occurred in the hands of those who have used the serum may help to its getting a fair trial and may be the means of not only saving the lives of patients, but of cutting short the attack and hence saving the patient from many of the sequela that folluw. From October, 1898, to October, 1900 I bave treated about 30 cases of this disease, the oldest patient being a child aged 13 years, and the youngest a child aged two years, and with the exception of half-a-dozen were treated with the antitoxin, the resuls being that of those treated with it only one of the number died, whereas of the six patients treated along the ordinary lines two died and two developed post-diphtheritic paralysis The two latter unfortunately neither at the time nor at any time of the treatwent showed a membrane, and I treated them for a simple angina of the throat. and it was not till the paralytic symptims developed that it stunck me that they had had diphtheria. These two cases were also the starting-pnint of an epidemic. In one case paralysis affected the limbs, whereas in the other case the thoracic muscles and the muscles of deglutition setmed to be especially affected; there was some loss of power in the arms, but the lower limbs seemed to escape altogett er.

In the case treated with antitoxin that resulted in death the patient was seen by me first on the ibild day of illness. He was 11 years old and at the time when I saw him he bad difficulty in breathing and in swallowing. On examining the throat $I$ found a membrane, somewhat greyish in colour, covering the vaso-pharynx, tonsils, and uvula with an offensive discharge from the nares and enlargement of the glands of the neck. After carefully washing the lumbar region with turpentine, rfctified spirit of wir $e_{\text {, and per- }}$ chloride of mercury ( 1 in 1000) I injected 2000 units of the serum obtained from Burrughs and Wellcome and at the same time ordered inhalations of carbolic acid. On calling again I found the boy much easier in his breathing and his father told me that he bad been able to swallow hir milk more easily and, in fact, was constantly callirg for some. On examining the thriat I found the membrane grtatly reduced. I then again ir jected 1560 anits of the serum and after leaving injunctions that the boy was on no account to be allowed to sit up left with the full conviction that he would do well. Suon after my leaving be conghtd up the membrane and slept soundly, but unforturately on his father leaving the room he sat up and tried to belp himself to some milk and fell back dead, death being due to carciac failure. This was a lesson to me in giving a prognoris, and in all my other cases I took care to place the patient on a carriac stimulant, the one generally used being a mixt ure contuining two drachms of solution of perchloride of iron, one drachm 